\title{
Implementation Procedure for a Designed Stand-alone, Auto- Frequency Select Ultrasound Pest Control Device for Field Applications
}

\author{
Aku G. Ibrahim ${ }^{\mathrm{a}^{*}}$, Onyedi D. Oyedum ${ }^{\mathrm{b}}$, Omotayo B. Awojowogbe \\ ${ }^{a, b, c}$ Department of Physics Federal University of Technology, Minna, Nigeria.
}

Received: 30 May 2017; Accepted: 11 September 2017; Published: 08 January 2018

\begin{abstract}
A detailed design description of a stand-alone, auto-frequency select, ultrasonic brand of electronic pest control device that is unique in the sense that: it is solar powered, pest specific, field/farm operated, audio back-up, auto-frequency select and multi-directional in nature was hitherto presented using design calculations and analysis supported by circuit diagrams and component specifications. In this work, the conceptualized design was physically realized to specification using electronic construction technology. Implemented section by section on breadboard before soldering onto a veroboard, the cased device was made to sit on a fabricated adjustable stand to provide the needed exposure both to crops and solar insolation. Result shows that the assembled device saturates the vicinity of broadcast with ultrasound capable of deterring weaver birds. Recommendation was made for a performance evaluation of the device in weaver birds infested farms.
\end{abstract}

Index Terms: Ultrasound, stand-alone device, implementation procedure, integrated circuit (IC), habituation, weaver birds.

(C) 2018 Published by MECS Publisher. Selection and/or peer review under responsibility of the Research Association of Modern Education and Computer Science.

\section{Introduction}

The absence of field survey in the area of ultrasonic pest control is one of the reasons responsible for the failure of ultrasonic pest control devices [1], [2]. In addition to field survey being a necessary requirement for an effective device, it was also extended, that ultrasonic pest control devices should be pest specific and site specific to overcome habituation [3]. In the light of these, an intensive field survey was carried out incorporating the concept of specificity. A locality bedevilled by weaver bird pests was identified and made the

* Corresponding author. Tel. +2348062382666

E-mail address: ibrahimaku@futminna.edu.ng 
study area [4,5,6 and 7]. The study among others revealed the mode of operation of the pest, existence of predators, effective local pest control methods, response to ultrasound of various frequencies, duration for habituation to ultrasound, stages of attack among others. The result of ultrasonic broadcast was used to generate bird-flight, bird return, and farm/feeding data. Analysis of the data identified ultrasound frequency of $35 \mathrm{kHz}$ as the put-to-flight and stay-away frequency at bird homes while $25 \mathrm{kHz}$ was effective in farms during feeding [8 and 9]. These interesting outcomes of the field study provided the requisite fundamentals to the feasibility of solving the peculiar pest problem of the locality electronically rather than chemically, which is prone to environmental contamination and eco-system distortion [10]. In view of this, a comprehensive electronic design incorporating the output of the field survey as design considerations was arrived at [11] and [12]. With the missing gap (field survey) filled and a design in place, the stage is set for the implementation of the designed solar powered ultrasonic weaver bird pest control device. In this work, the design concepts captured in lines, symbols and mathematical calculations was physically realized using electronic construction technique.

\section{Methodology}

The methodology adopted in this work is that of electronic construction technology in which a designed, tested and simulated circuit is technically assembled with the overall objective of giving birth to the conceived intention of the designer for the benefit of targeted audience.

\subsection{Design Re-presentation}

The design was grouped into ten sections and each section elaborately discussed in terms of design considerations, design calculations, component specifications and circuit diagrams [12]. The overall circuit schematics with each constituent labeled 1 to 13 is here re-presented in Fig. 1.

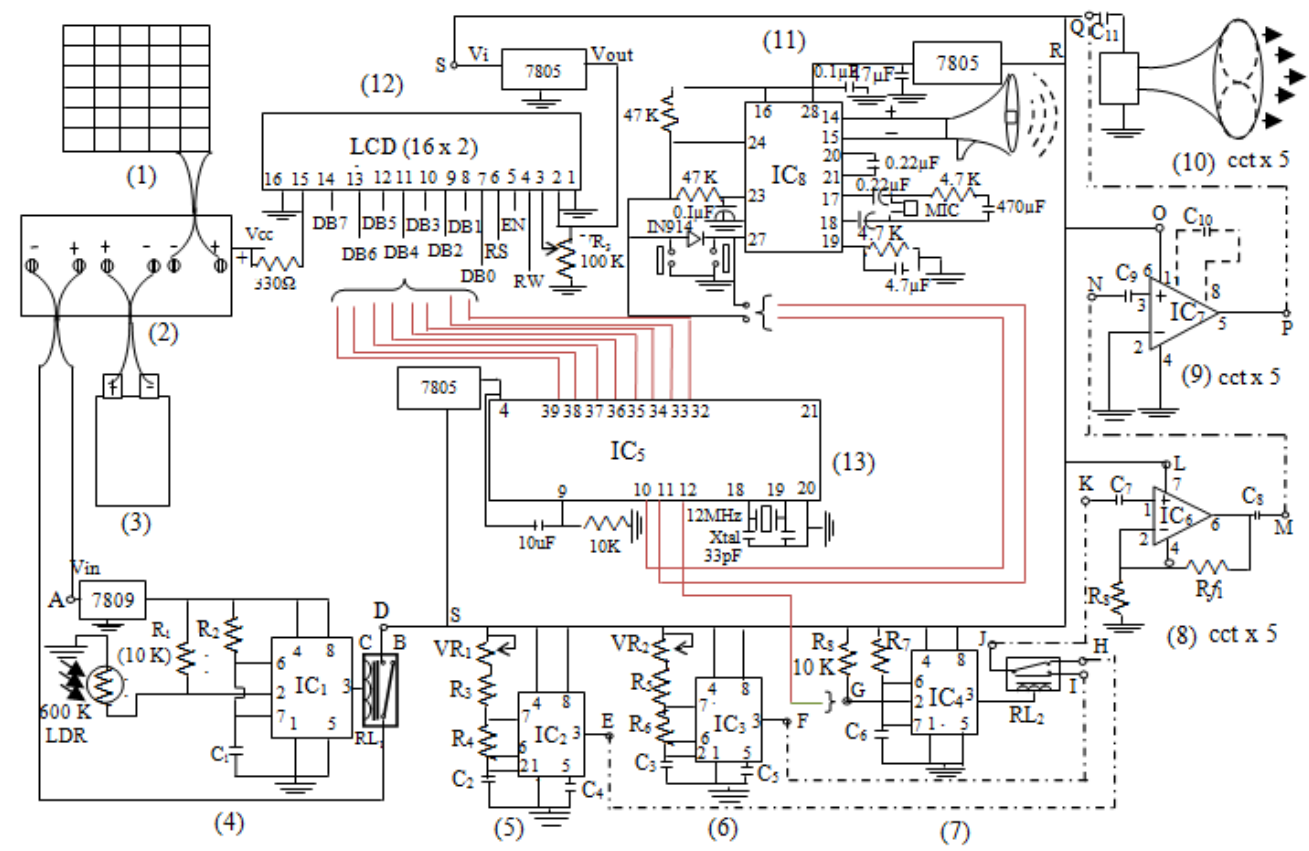

Fig.1. Overall Circuit Diagram of the Designed Stand-alone Solar Powered Ultrasonic Device [12] 
The labelling of Fig. 1 is as follows:

1. Solar Panel

2. Charge Controller

3. Battery

4. Tripping Circuit

5. $25 \mathrm{kHz}$ Oscillator

6. $35 \mathrm{kHz}$ Oscillator

7. Frequency Selection Circuit

8. Pre-amplifier Circuit

9. Power Amplifier Circuit

10. Ultrasonic Transducer

11. Predator Cry

12. Visual Display Section

13. Microcontroller Circuit

Power Line

Ultrasonic Signal Line

Electronic Communication Line

Electronic circuit implementations are carried out in line with conceived design [13]. Therefore, the implementation of the overall circuit to give rise to the standalone ultrasound pest control device was in accordance with previously presented design and the circuit diagram presented in Fig. 1.

\subsection{Material survey}

The choice of materials used in terms of specification and component values were carefully arrived at during the design stage. All the parts were sourced and assembled locally from electronics part dealers. In cases where the exact calculated values of components were not available in the market, the closest practical values commercially available were used.

\subsection{Assembly of Parts}

This electronic design was first implemented on a breadboard, section by section, for easy debugging. After demonstrating that it works properly, the circuit was "hard-wired" or soldered onto a veroboard. The choice of a veroboard was because of the linear pattern its copper tracts are laid and for its convenience compared with others. Building the circuit on veroboard was started by soldering the components on the copper tract one after the other in line with the circuit diagram shown in Fig. 1. The assembled circuitry of the stand-alone ultrasound device is shown in Fig. 2.

\subsection{Implementation Procedures}

The circuit was implementation section by section as discussed below:

\subsubsection{Implementation of the Power Supply Section}

The power supply section comprises of the solar panel, solar charge controller and batteries. The $18 \mathrm{~V}$ polycrystalline solar panel labelled as number 1 in Fig. 1 was directly connected to the charge controller labelled as 2 . An extension was made from the charge controller via connection cables and a socket soldered to 
it's end. This allows the controller's solar panel inlet terminal to be extended to the surface of the casing and from where the solar panels cable can be inserted and disconnected easily via an inlet plug. The two 12V, 7.2 $\mathrm{Ah} / 20 \mathrm{hr}$ rechargeable batteries labelled as number 3 in Fig. 1 were both connected in parallel and the positive and negative ends connected to their respective terminals on the charge controller. With the solar panel plugged into the socket and the battery connected as shown in Fig. 1, the solar panel indicator (LED) on the charge controller will automatically be turned $\mathrm{ON}$ while the battery indicator will start blinking, indicating that charging has commenced.

\subsubsection{Implementation of Tripping Section}

The tripping section and other successive sections of this design constitute the load which the power section seeks to drive. Hence, the tripping circuit labelled as 4 in Fig. 1 was connected from the load terminal of the charge controller to shut down the active and successive sections at evenings and to trip ON early in the day when the birds will be present on the farm. This section was introduced into the design to help delay habituation which would result from a continuous operation of the device and to conserve battery energy. The major components in this section are the $600 \mathrm{k} \Omega$ photo/light resistor (Light Dependent Resistor, L.D.R) and a 555 timer $\left(\mathrm{IC}_{1}\right)$ connected in a monostable mode. The $9 \mathrm{~V}$ requirement of the IC was tapped from the $12 \mathrm{~V}$ load line into the voltage regulator 7809 at point A. The IC's output (pin 3) was connected to the relay $\left(\mathrm{RL}_{1}\right)$ which is made to toggle anytime the IC's input is excited by the LDR. A long cable was soldered from the IC input track to the LDR in order to provide an extension to the surface of the casing. At the created space on the surface of the casing, the LDR will detect the presence and absence of sun light for the activation and deactivation the ICs input based on the adjusted photo limit. The outcome of this procedure is to enable the relay to toggles from position $\mathrm{B}$ to $\mathrm{C}$ and from $\mathrm{C}$ to $\mathrm{B}$ thereby connecting to or disconnecting from the load line of the charge controller to energies or de-energies the power line respectively with $12 \mathrm{~V}$ at point $\mathrm{D}$, from where the entire circuit will tap from.

\subsubsection{Implementation of the $25 \mathrm{kHz}$ and $35 \mathrm{kHz}$ Oscillators}

The 25 and $35 \mathrm{kHz}$ oscillators were labelled as 5 and 6 respectively in Fig. 1. With the resistors and capacitors assembled and the $\mathrm{IC}^{\prime} \mathrm{s}\left(\mathrm{IC}_{2}\right.$ and $\mathrm{IC}_{3}$, both 555 timers) connected as designed in astable mode, extension wires were attached to the variable resistors $\mathrm{VR}_{1}$ and $\mathrm{VR}_{2}$ so that they can be positioned on the casing and adjusted externally when necessary. As implemented and with the variable resistors proportionately adjusted, the sections generate the targeted ultrasound frequencies of 25 and $35 \mathrm{kHz}$ available at terminals $\mathrm{E}$ and $\mathrm{F}$ respectively.

\subsubsection{Implementation of Frequency Selection Section}

The frequency selection section is labelled as 7 in Fig. 1 . The function of this section is to select between the output of the 25 and $35 \mathrm{kHz}$ oscillator at stipulated intervals of fifteen seconds. The major components here are the 555 timer $\left(\mathrm{IC}_{4}\right)$ and the microcontroller AT89C52 $\left(\mathrm{IC}_{5}\right)$. The 555 timer is connected in monostable mode with the microcontroller as its external excitation agent. In-line with the circuit design and calculations [10], this section as implemented will have the microcontroller sending pulses every fifteen seconds to $\mathrm{IC}_{4}$ causing its output to toggle the relay $\mathrm{RL}_{2}$ between two extremes. The output of the two oscillators, $\mathrm{IC}_{2}$ and $\mathrm{IC}_{3}$ were tapped from points $\mathrm{E}$ and $\mathrm{F}$ via cables and soldered to points $\mathrm{H}$ and I which serve as extended terminals. The microcontroller's frequency selection program written in Assembly language was addressed to port 3.1 (pin 11) and a connection established between the microcontrollers $\left(\mathrm{IC}_{5}\right)$ pin 11 and timers $\left(\mathrm{IC}_{4}\right)$ input at point $\mathrm{G}$ (pin 2).The choice of the values of the timing components responsible for the frequency selection timing $t$, were guided at design and implementation stages by the equation; 


$$
t=1.1\left(R_{7}+C_{6}\right)
$$

When implemented, the microcontroller sends trigger pulses every fifteen seconds to the 555 timers trigger input (pin 2), thereby disconnecting from one oscillator, say $25 \mathrm{kHz}$ oscillator at point $\mathrm{H}$ and establishing contact with the $35 \mathrm{kHz}$ oscillator at point I at time interval of fifteen seconds. This is maintained until another fifteen seconds elapses and another trigger from the microcontroller is required. The essence is this section is to introduce a measure of variability into the ultrasound signal as the birds are controlled both at home and in the farm. This is necessary to delay habituation as stated in the design considerations [1].

\subsubsection{Implementation of the Predator Cry Section}

This section was implemented as designed and labelled as number 11 in Fig. 1. Its function is to play selected sound/cry of weaver birds predators for the purpose of fortifying the device in times of habituation. The central component here is the ISD2560 $\left(\mathrm{IC}_{8}\right)$ for its solid state voice reproduction. Previous study at the study area [8] identified predators, local bird scaring methods and other effective scaring measures. These audio sounds are namely: those of the dreaded hawk, dog, man and the distressed cry of weaver birds under predator attack, were all recorded during the field study using audio recorder. $\mathrm{IC}_{8}$ was connected in factory specification as shown in number 11 of Fig. 1 and the record button depressed, the IC effectively recorded the relayed audio sounds for fifteen seconds each and clearly replays the sounds when the play button was depressed. The IC's connection as implemented from the design was in mode 4. In this mode, skipping between recorded tracks is permitted as controlled by the microcontroller. Both the microcontroller and ISD2560 were linked via port 3.0 (pin 11) and port 3.1 (pin 10) of the microcontroller and pin 27 and pin 23 of the ISD2560. Cable connections were established between the relevant pins and extended in order to allow for external selection of desired predator sound by a user. The output was interfaced with an independent megaphone for audio transmission of selected predator cry. The $5 \mathrm{~V}$ requirement of the $\mathrm{IC}_{8}$ was tapped from the power line through voltage regulator 7805 at point $R$.

\subsubsection{Implementation of Visual Display Section}

The device communicates with users visually using the visual display as controlled by the microcontroller. A sixteen by two (16 x 2) segment Liquid Crystal Display (LCD) was implemented according to circuit diagram labelled as number 12 in Fig. 1. It visually displays the current frequency and predator cry selections. The major procedure here is the implementation of the electronic communication lines between Pin 7 to pin 14 (DB ports) of the LCD (number 12) and port 0 (pins 32 to 39) of the microcontroller (number 13) as shown in Fig. 1. By so doing, the microcontroller alerts the LCD of its communication with the frequency selection section and the predator section for effective visual display of the current frequency of transmission and currently selected predator cry. The supply voltage was tapped from point $S$ through voltage regulator, 7805.

\subsubsection{Implementation of Microcontroller Section}

The implementation of this section is such that the microcontroller, AT89C52 ( $\left.\mathrm{IC}_{5}\right)$ will exercise control over three sections previously discussed: the frequency selection section, the predator cry section and the visual display section. Labelled as 13 in Fig. 1, links of electronic communication lines between the microcontroller and these sections were illustrated. The program written in Assembly language was debugged and burnt into the chip.

The program steps are as follows: 
1. On powering the microcontroller, it sends a pulse to $\mathrm{IC}_{4}$ of the frequency selection circuit, causing it to change state and toggles the $5 \mathrm{~V}$ relay $\left(\mathrm{RL}_{2}\right)$ and thereby selecting the $35 \mathrm{kHz}$ frequency.

2. The microcontroller messages the LCD to display "Current Frequency mode is $35 \mathrm{kHz}$ ".

3. After 15 seconds, another pulse is sent to $\mathrm{IC}_{4}$ causing it to change state and toggle the relay, thereby disconnecting from the $35 \mathrm{kHz}$ and connecting to the $25 \mathrm{kHz}$ frequency.

4. The microcontroller messages the LCD to display "current frequency mode is $25 \mathrm{kHz}$ ".

5. When the pins concerned with each of the four predator sounds is activated. Instructions are sent to the corresponding memory location of the $\mathrm{ISD}\left(\mathrm{IC}_{8}\right)$ from the microcontroller to play the audio sound recorded in that location.

6. The microcontroller communicates with the LCD to display the current audio sound being played, such as "current sound is hawk sound", "current sound is dog barking", "current sound is human voice" and "current sound is distressed sound".

\subsubsection{Implementation of Preamplifier Section}

Implementation of the design from this stage forward was executed in five segments, each a replica of itself. The uniqueness of this design is also seen in its multi-directional nature. Ultrasound so generated was amplified and transmitted in five directions, four oriented $90^{\circ}$ horizontally and one directed downward. As such, the preamplifier section and other subsequent sections to be discussed were executed in five segments, each to take care of a specific direction. Although, a single arm will be discussed. This arm was illustrated on the right hand side of Fig. 1 by "cct x 5", meaning the circuit was executed in five segments. The preamplifier section was implemented in accordance with the circuit labelled as 8 in Fig. 1. The circuit as designed [9] will raise the level of the ultrasound input signal by 500 . The major component here is the UR741 ( $\left.\mathrm{IC}_{6}\right)$, the supply voltage was connected from the power line through point $\mathrm{L}$ and the output of the frequency selection circuit was tapped from point $\mathbf{J}$ via cable to point $\mathrm{K}$, the input of the preamplifier. Thus, making its input at $\mathrm{K}$, an intermittent selection of raw $25 \mathrm{kHz}$ and $35 \mathrm{kHz}$ ultrasound signal every fifteen seconds. While it's output at $\mathrm{M}$, an intermittent selection of $25 \mathrm{kHz}$ and $35 \mathrm{kHz}$ ultrasound signal preamplified by a factor of 500 every fifteen seconds.

\subsubsection{Implementation of Power Amplifier}

The major component of the power amplifier section is the $\mathrm{LM} 386$ operational amplifier $\left(\mathrm{IC}_{7}\right)$ as labelled 9 in Fig. 1. The IC has a natural amplification of 20, but was modified in line the design by soldering a $10 \mu \mathrm{F}$ capacitor between pin 1 and 8 as shown by the dotted line. With this modification, the IC has the capability of a gain of 200. The IC's signal input (point N) on pin 3 was tapped from the preamps output at point M. The intention for a gain of 100,000 was achieved by multiplying the output of both the preamplifier and power amplifier at point $\mathrm{M}$ and $\mathrm{P}$ respectively.

\subsubsection{Implementation of the Ultrasonic Transducer Section}

The ultrasonic transducer section serves as the ultrasound output of the device. It converts the generated and amplified ultrasound electrical signal into its equivalent mechanical sound. This section is labelled as 10 in Fig. 1. In line with the design, dual diaphragm-dual outlet twitters of stated specification, prominent among which is a frequency response covering the entire generated frequencies. The specification of the ultrasonic twitters used to implement this section is shown in Table 1. 
Table 1. Specification of Ultrasonic Twitters

\begin{tabular}{ll}
\hline Specification & Rating \\
\hline Frequency & $4-50 \mathrm{kHz}$ \\
Sensitivity & $95 \mathrm{~dB} 2.83 \mathrm{~V} / 1 \mathrm{M}$ \\
Power & $75 / 300 \mathrm{~W}$ \\
Impedance & $4-8 \Omega$ \\
Size & $6 \times 3 \mathrm{~cm}$ \\
Net Weight & $135 \mathrm{~g}$ \\
Type & Piezoelectric \\
& \\
\hline
\end{tabular}

The specification in Table 1 covers the entire frequency spectrum stated in the design and was connected as shown in Fig. 1. The power amplifiers output was tapped from point $\mathrm{P}$ to $\mathrm{Q}$ and a coupling capacitor $\mathrm{C}_{11}$ of value $220 \mu \mathrm{F}$ was used to couple the twitters. A total of five twitters were used to serve as load on each of the power amplifiers of each segment.

The picture of the final assembled circuit before casing is shown in Fig. 2. It constitutes the main circuit panel of the device and works with other accessories to achieve over all designed intent.

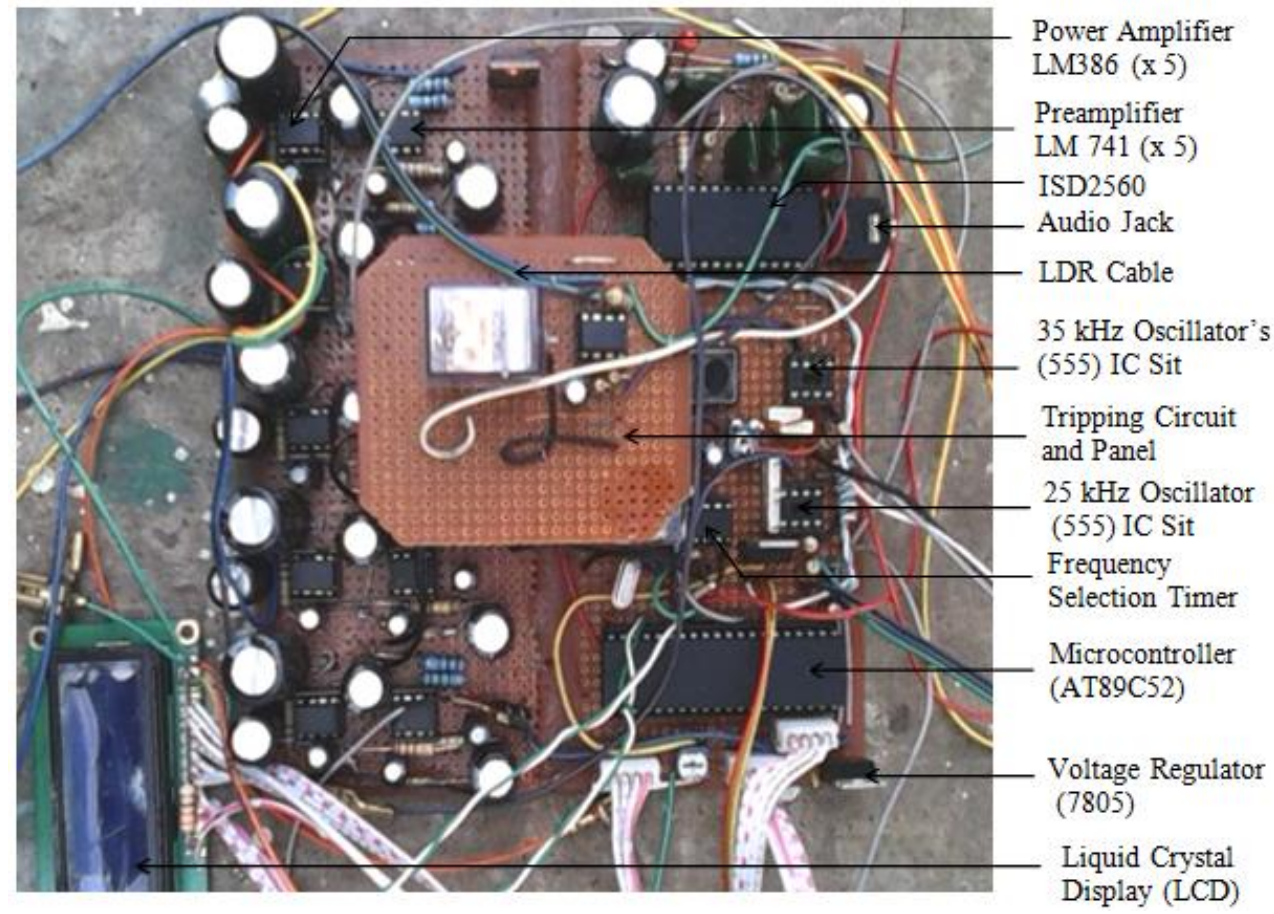

Fig.2. Circuitry of the Stand-alone Device

\subsection{Design and Implementation of Casing}

The casing was thought of as an embodiment capable of adequately housing the circuitry and hosting its accessories. Operational buttons which are to serve as interface between the internal circuitry and users were 
also lodged on the casing. In view of these, the size, morphology and nature of material of the casing are of paramount importance. Taking into consideration the sizes of the circuitry and associated larger components such as batteries and ultrasonic twitters, solar charge controller and the reasonable allowances for ventilation, a box of dimension $43 \mathrm{~cm} \times 36 \mathrm{~cm} \times 18 \mathrm{~cm}$ was chosen. For the casing material, a thermoplastic transparent material known for its toughness and insulating properties was chosen. A rectangular opening (broadcasting outlets) of dimension $13 \mathrm{~cm} \times 6 \mathrm{~cm}$ was made on each sides and one at the bottom from where ultrasonic twitters will transmit ultrasound signal through. The front view was over laid with a gold plated reflective metal sheet for a better aesthetics. This reflective surface apart from given the device a beautiful outlook, also gives an open invitation to the birds which are well known to be attracted to such surfaces.

The materials were sourced and cut into designed sizes, screws and glues were used to fasten the thermoplastic material to junction sticks. Outline of where components such as batteries, ultrasonic transducers, solar charge controller and circuit panel will be fixed were drawn in the box and later mounted with the aid of screws and glues. The photograph showing the mounted circuitry and casing interior is shown in Fig 3 .

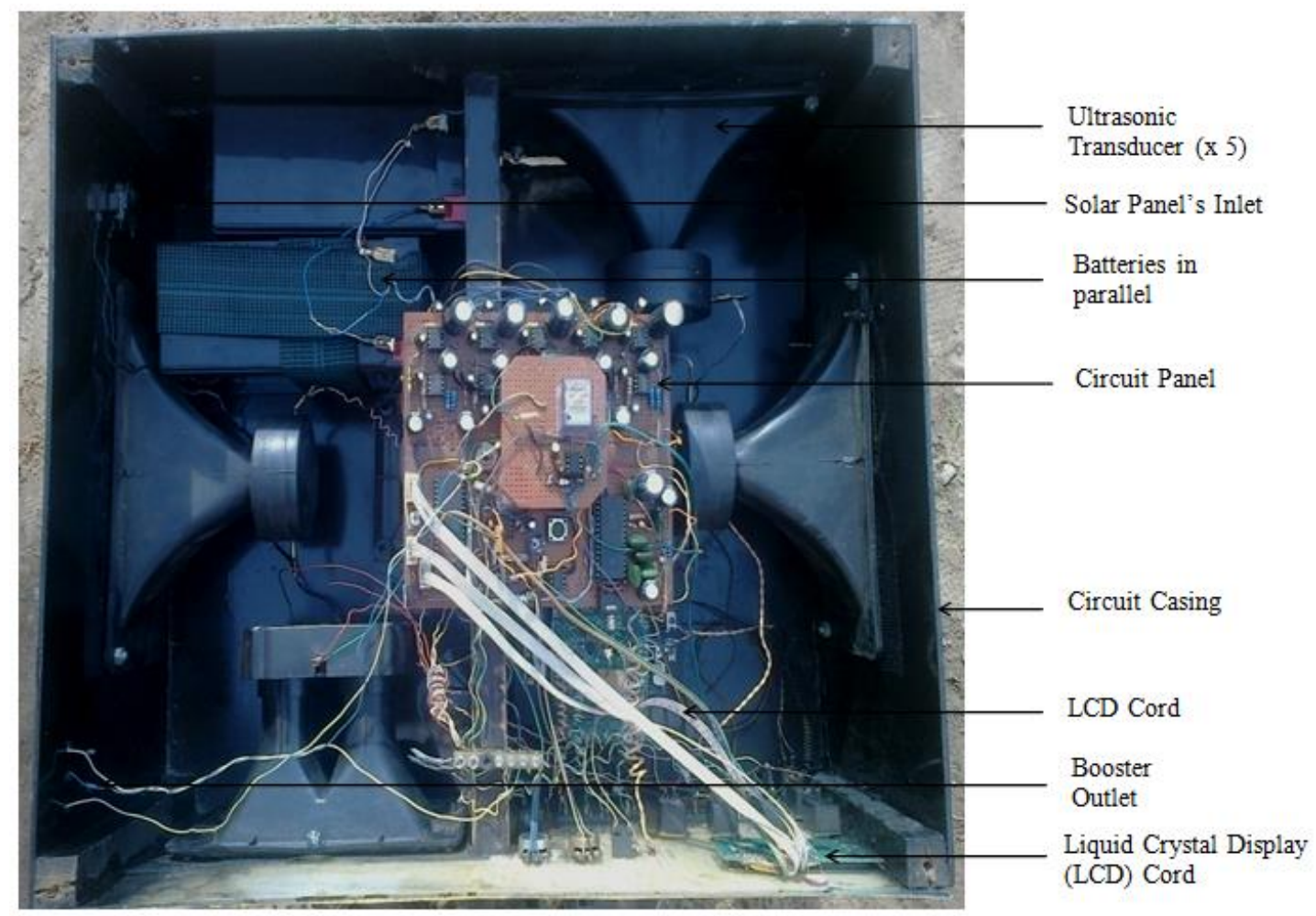

Fig.3. Circuitry and Casing Interior

The following casing connections were made

- The solar panel inlet terminal was created by making an extension from the charge controller's solar panel terminal via connection cables to the rear left-hand side of the casing and a socket soldered to it, from where solar panel input plug can be inserted. 
- $\quad$ Four ultrasonic twitters were screwed to the rectangular openings on each side of the casing and the fifth was screwed to the bottom to form the five broadcasting outlets for ultrasound signal transmission. A soft wired net was used to seal the openings to prevent unauthorized access into the twitter.

- The circuit panel was screwed on top of the bottom twitter. As seen in Fig 3, the bottom twitter is not visible as the panel sits directly on top of it.

- The solar charge controller was positioned on the bottom cover. Not visible on Fig. 3 because of the multiple cable connections made from it. Three LED's originally imbedded on the solar charge controller were extended via cables to the front cover. These are the red, blue, green LED. The red is to indicate that the solar panel is connected and charging the battery, the blue to indicate power delivery to the load and the green to indicate the state of the battery whether fully charged (green), empty (red) or moderately charged (yellow).

- $\quad$ The Liquid Crystal Display (LCD) cable was extended and positioned on the top-right of the front side by making insertion on the casing into which it was fitted and screwed.

- The Light Dependent Resistors (LDR) cable was extended and positioned above the LCD to allow for maximum exposure to sunlight.

- The variable resistors VR1 and VR2 connected to the $25 \mathrm{kHz}$ and $35 \mathrm{kHz}$ oscillators respectively were removed from the panel. Cables were soldered to their terminals and were extended and positioned on the front side of the casing with their knob projecting outward to allow for external adjustment by a user.

- Predator cry switches (toggle switches) were created by making connections from relevant pins on the microcontroller to the casing such that their activation will trigger the respective predator cry to be sounded. Also, is the LED on the ISD, it was extended to the casing to indicate when audio sounds are activated.

- $\quad$ External twitter sockets were formed by extending from the internal twitters to allow a user to externally connect and extend a maximum of four ultrasonic twitters to favourite feeding spots of the birds.

- A booster outlet was fashioned for future design purposes. Raw ultrasound can be sourced from this terminal and transferred to another device for processing and boosting. This was achieved by tapping from point $\mathrm{J}$ (after the frequency selection circuit) to the casing. $9 \mathrm{~V}$ power was also tapped to the terminal to serve as power supply for the proposed booster device.

The following features are visible on the casing: the power switch, two frequency knobs (25 and $35 \mathrm{kHz})$, LCD screen, audio section indicator, audio outlet, four predator sound selection switches, four external twitter sockets, three buttons (power, battery and reset), three LEDs (for battery, load and solar panel indication), solar panel input socket, Light Dependent Resistor orifice, booster outlet and a signal broadcasting outlet (13 cm x 6 $\mathrm{cm}$ ) on each of the four vertical sides and one on the bottom. The frontal view of the finished work was overlaid with a shiny, reflecting golden coloured metal sheet on which projected features were labelled. The position of the L.D.R was left uncovered in order to give it the needed exposure to the triggering parameter of daylight. Photograph of the frontal view of the stand-alone device are shown in Fig. 4. 


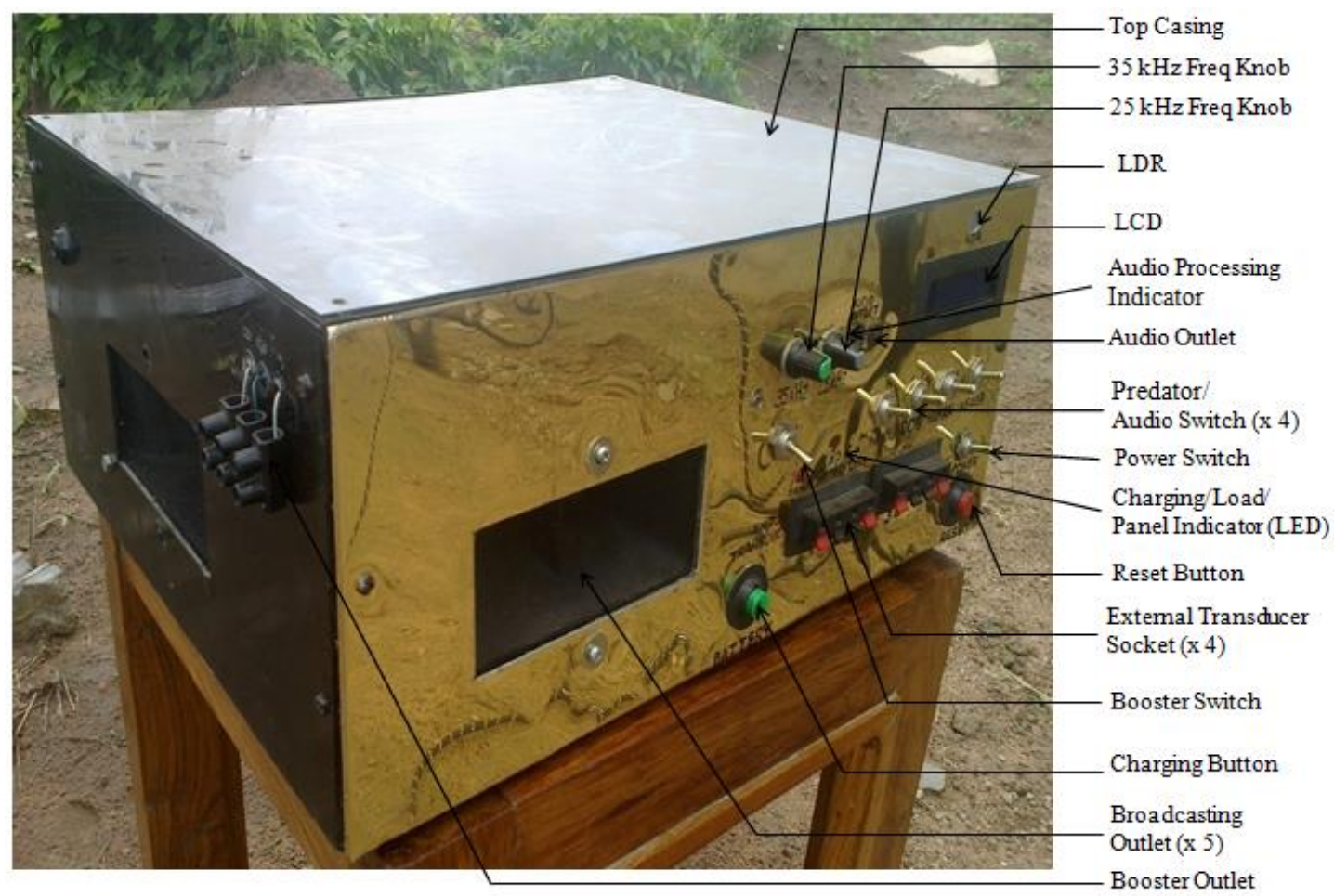

Fig.4. External Top, Side and Frontal View of Device

\subsection{Design and Fabrication of Adjustable Stand}

The design concept for the stand is such that it stands on three foldable legs for better balancing and portability. There is need to elevate the device to same height as the pest targeted point of the crop. An adjustable trunk capable of upward and downward movement was conceived. Millet, sorghum and rice, for example, have their pest target points located at their topmost part. This allowance will allow for its application to tree crops and bird homes. A levelled surface on which the device will rest is also required. For this, a sizable horizontal detachable platform with opening provided for the bottom broadcasting outlet was considered appropriate.

The design was implemented through metal fabrication. So, the stand-alone device will sit on a three-legged adjustable stand which can be adjusted from a height of 1.2 metres to 6.0 metres. A detachable horizontal platform of dimensions $67 \mathrm{~cm} \times 55 \mathrm{~cm}$ was mounted on the trunk and on top of which the devices will sit. A little portion of the platform having dimension $13 \mathrm{~cm} \times 6 \mathrm{~cm}$ was opened to provide space for the bottom broadcasting outlet. This stand helps to raise the device to the same height with the crops. Since ultrasound is prone to absorption by intervening bodies, the adjustable stands will help in achieving this levelling needed for better interaction between the signal and the pest in different farm types. Fig. 5 is a picture of the adjustable stands with horizontal platforms for the stand-alone device. 


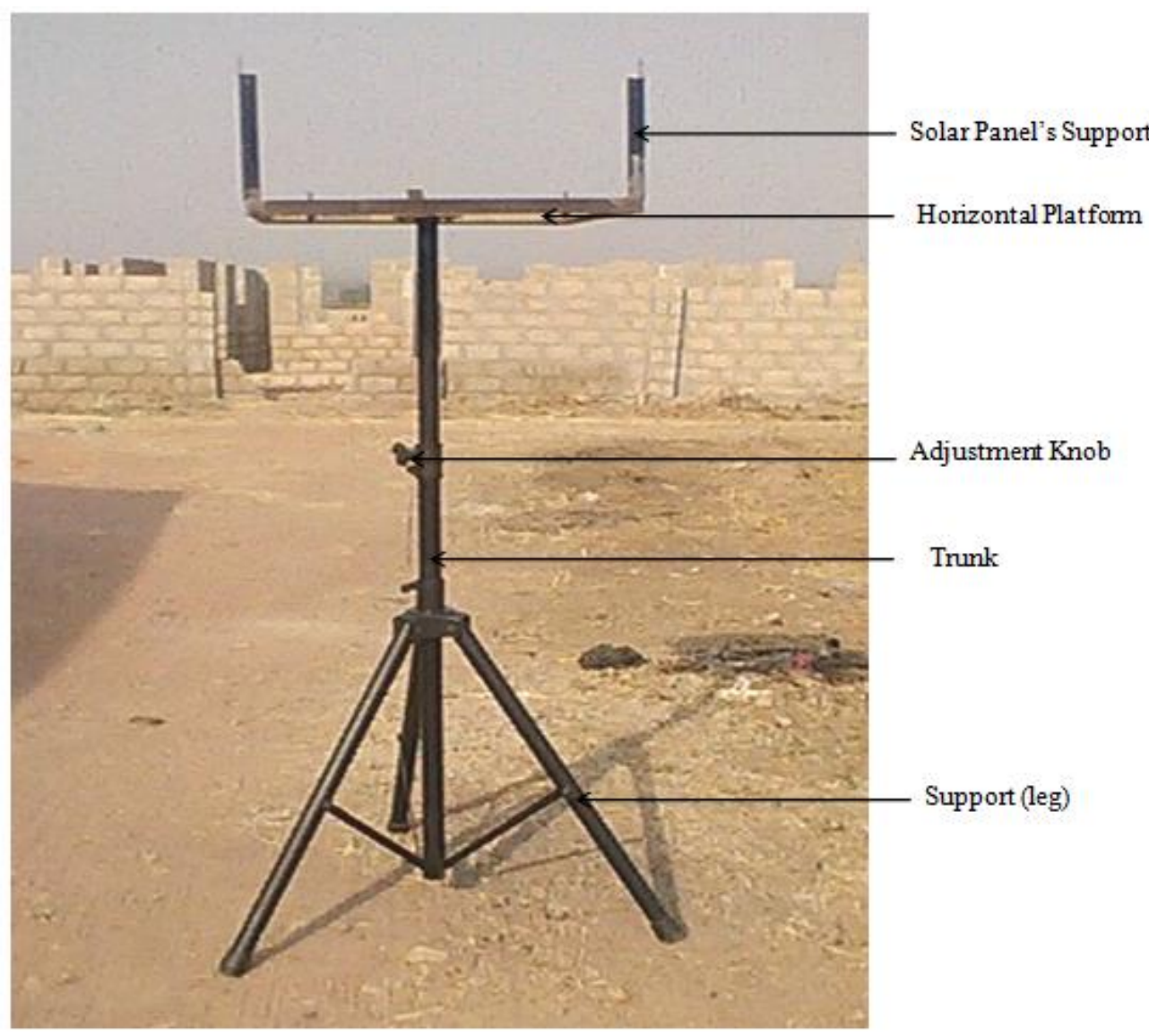

Fig.5. Adjustable Stand with Horizontal Platform for the Stand-alone Device

\subsection{Mounting of Solar Panel}

The stand-alone device is solar powered via a characterized polycrystalline solar panel [14 and 15]; the solar panel will require maximum exposure to sunlight, most preferably, above the ground surface. Also, is the ultrasound device being an outdoor (field) device, requiring a roof as a cover from rain, mist, dust and sun which are all detrimental to the circuit. As a matter of innovation, a symbiosis relationship where the solar panel provides shelter to the device while the solar panel enjoys maximum exposure to solar radiation as it rest on the device and adjusted above the surface during operation. The tilt and orientation of a solar panel which refers to the position of the solar panel relative to the sun, and how this impact on the amount of energy captured by the panel is also of interest. Solar panels are inclined at an angle as close to the locations latitude as possible, to absorb maximum amount of energy (solar gain). Niger State, Nigeria is located between latitudes $8^{\circ} 20^{\prime} \mathrm{N}$ and $11^{\circ} 30^{\prime} \mathrm{N}$ and longitude $3^{\circ} 30^{\prime} \mathrm{E}$ and $7^{\circ} 20^{\prime} \mathrm{E}$. Therefore the solar panel (roof top) was tilted at an angle of $10^{\circ}$ (latitude average) due south. In this position, the panel enjoys maximum exposure at both sun rise and sun set. Therefore, the roof in this context serves for a cover and as a source of maximum power. The solar panel, however, does not make contact with the device. This was achieved with the aid of two vertical supports of $8 \mathrm{~cm}$ from the platform, at the front and a $15 \mathrm{~cm}$ long stopper at the rear, to give the desired orientation. Fig. 6 shows the picture of the solar panel mounted on the stand. 


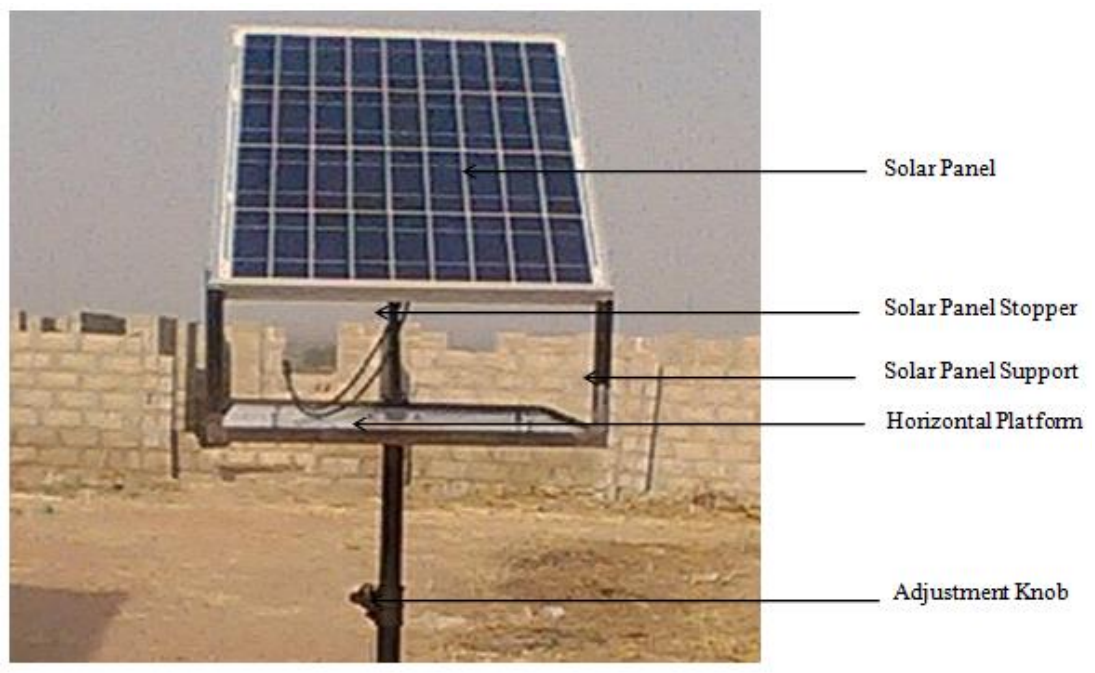

Fig.6. Adjustable Stand, Horizontal Platform with Mounted Solar Panel

\section{Result and Discussion}

The outcome of the implementation procedures for the circuitry, casing and adjustable stand is the birth of a complete set of the stand-alone ultrasound device capable of transmitting high penetrating ultrasound in five independent directions capable of deterring weaver birds away from farms. Fig. 7 and 8 shows the complete set up of the stand-alone device.

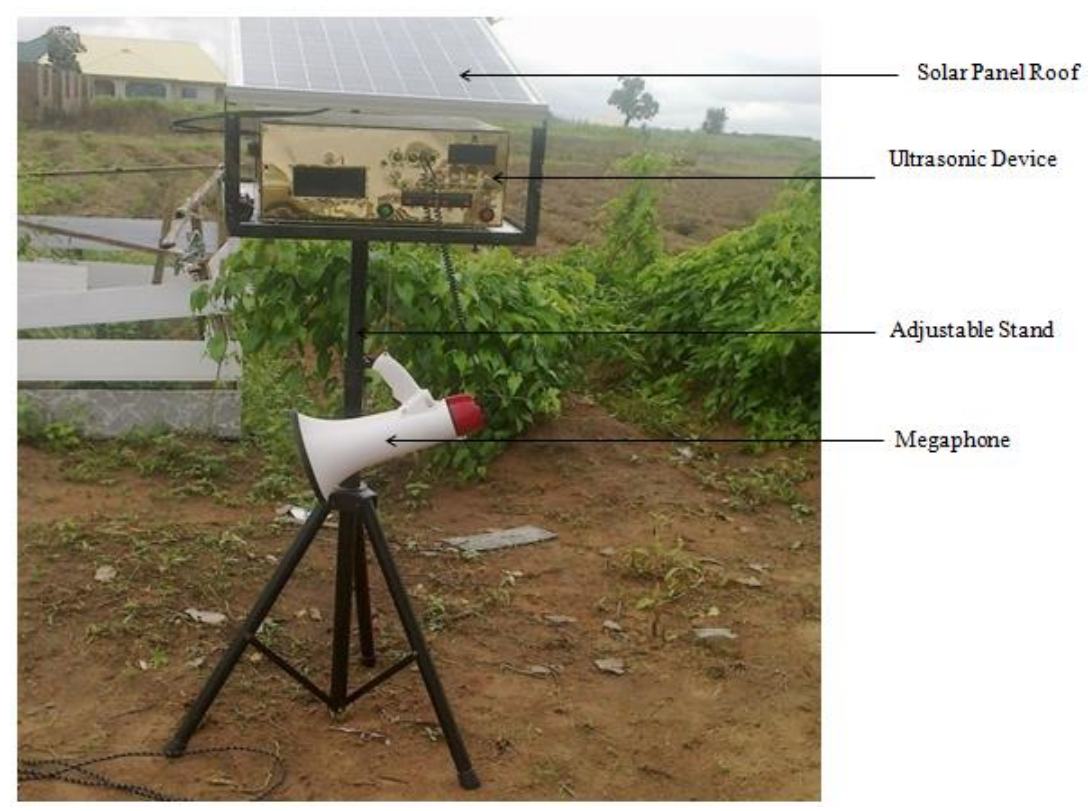

Fig.7. Set-up of the Stand-alone Mode of Operation 


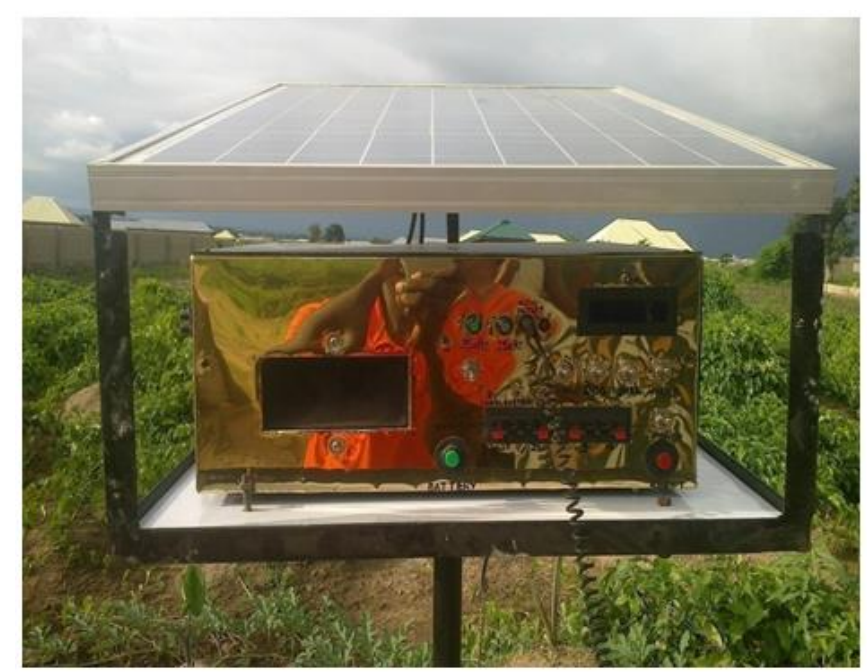

Fig.8. Near View of the Set-up

To operate the device in stand-alone mode while on a farm, the following steps were followed:

i. The stand was coupled by adjusting the legs and attaching the horizontal platform as shown in Fig. 5 .

ii. The device was placed on the platform and fastened;

iii. The solar panel was placed above the device by screwing the front end to the vertical support and the rear was hooked to the stopper as shown in Fig. 6 . In this position the solar panel is at the required angle of $10^{\circ}$ to the horizontal;

iv. The whole arrangement was rotated so that the solar panel faces south. This provides the required direction for an all day long exposure to the sun's rays;

v. The solar panel's cable was plugged into the device's solar panel inlet and the charging button was pressed to commence charging the battery;

vi. The stand was adjusted to about the same height as the crop. This levelling is necessary for better interaction with target part of the crops;

vii. Pressing down the power button makes the supply voltage $\left(\mathrm{V}_{\mathrm{CC}}\right)$ available to the tripping section. If it is daytime, the section automatically clicks and feeds the supply line to power the other sections. But at evening times, this section trips OFF, disconnecting the other sections. When tripped ON, the timing section sets the frequency with which each of the oscillators will operate. The 25 and $35 \mathrm{kHz}$ frequency signals generated by the oscillators are intermittently selected at 15 seconds interval by the frequency selection section and passed to the amplifiers. The amplifier energises the signal and channels it to the ultrasonic transducer for broadcasting;

viii. When habituation is observed to be setting in after about three weeks of operation (according to field surveys result), the megaphone is hung on its hanger and the input jack is slotted into the stand-alone device's audio outlet. The predator cry section (audio section) was activated by selecting the desired predator option to release the recorded predator sound for broadcast by the megaphone. Independent ultrasonic twitters can be attached to the external transducer socket, thereby given a user a choice of extending the ultrasonic twitters away from the stand to more favourite feeding spots of the birds.

The preliminary testing procedure itemised above reveal that the device transmits high intensity and penetrative ultrasound signal. The five segments of transmission guarantee that the entire vicinity is kept 
saturated with ultrasound of required properties capable of repelling weaver birds away from the area of deployment. In addition to this is the audio section which plays selected sound of four predators to further fortify the device against habituation.

\section{Conclusion and Focus of Future Research}

The implementation of the overall circuit was done in accordance with circuit design, attainment of quality and low cost. All the parts were sourced, assembled and fabricated locally (within Nigeria). The electronic incorporation of the postulates for curbing habituation which is a daunting factor on the path of the effective implementation of ultrasonic pest control devices has settled the controversies surrounding its usage. The overall objective of this line of study which is to utilize ultrasound technology to implement an alternative ecosystem and environmentally friendly pest control method that can keep targeted weaver birds away from farms has been largely achieved. There is no doubt, that ultrasonic pest control devices which has hitherto remained as an experimental piece have by this work been fortified to be effectively deployed out of the laboratories and households into the field/farm to evaluate their performance in line with intended objectives. This however is the focus of future research.

\section{References}

[1] Ibrahim, A.G., Oyedum, O.D., Awojoyogbe, O.B., Okeke, S.S.N. Electronic Pest Control Devices: Their Necessity, Controversies and Design Considerations. The International Journal of Engineering and Sciences (IJES), 2013; 2(9), pp 26-30.

[2] Ibrahim, A.G., Oyedum, O.D., Awojoyogbe, O.B., Okeke, S.S.N. Developmental Features and Implementation Challenges of Electronic Pest Control Devices in Developing Countries. International Journal of Scientific \& Engineering Research (IJSER), 2014); 5(2), pp 411- 416.

[3] Ibrahim, A.G. Development and Performance Evaluation of a Solar Powered Ultrasonic Device for the Control of Weaver Birds in Farms. A Ph.D Thesis, Department of Physics, Federal University of Technology, Minna, Nigeria. 2015.

[4] E.O. Bright. Aspects of Ecology Pest Status and Control of P. cucullatus Muller and Q.erythrops Hartlaub in the Rice Fields in Niger State, Nigeria. University of Ibadan M. Phil dissertation. 1995.

[5] E.O. Bright Species Composition of Weaver Bird pests of Rice in Badeggi, Niger State, Nigeria. Int. Rice Res. Newsl.1988; 13(6): pp 43.

[6] E. O. Bright \& S. Ogunyemi. Diet and Foraging Habits of Village Weaver Bird Ploceus cucullatus and red-headed quelea Quelea erythrops in rice field habitats. Afr. J. Pl. Prot. 2000; 10: pp 71-81.

[7] E.O Bright, E.B Tologbonse and S. Ogunyemi. Farmers' Perceptions and Management Practices of Weaver Bird Pests in Niger State, Nigeria. Production Agriculture and Technology. 2009; 5(1):pp 1-13.

[8] Ibrahim, A.G., Oyedum, O.D., Awojoyogbe, O.B, Ezenwora, J.A and Aje, J.D. Pest and Environmental Specific Application of Ultrasound in Pest Control. Advances in Multidisciplinary and Scientific Research, 2016; 2(4):189 - 200.

[9] Deepali, G., Balwinder, S., Harpreet, S. Design and Development of Pesticide Residue Detection System using EC and pH Sensor. International Journal of Engineering and Manufacturing (IJEM), Vol.6, No.2, pp.10-17, 2016.DOI: 10.5815/ijem.2016.02.02.

[10] A.G. Ibrahim, O.D. Oyedun, O.B. Awojoyogbe. S.N.N. Okeke. Design, Construction and Characterisation of an Ultrasonic Device for the Control of Birds in Farms. A paper presented at the National Institute of Physics Conference held in March 2013 in Abuja, Nigeria.

[11] A.G Ibrahim, O.D Oyedum, O.B Awojowogbe,"Design Description of a Stand-Alone, Auto-Frequency Ultrasonic Brand of Weaver Bird Pest Control Device for Field Applications", International Journal of 
Engineering and Manufacturing(IJEM), Vol.7, No.5, pp.1-15, 2017.DOI: 10.5815/ijem.2017.05.01

[12] Usifo, O., Research Project Implementation Made Ease, first Edition. ECAS Ltd, Nigeria; 2004.

[13] Oyedum, O.D., Ugwoke, P.E., B.M Olomiyesan, B.M., Ibrahim, A.G. Performance Evaluation of Polycrystalline Silicon Module under outdoor conditions in North Central, Nigeria. Nig. J. Phy., Special Edition, 2014; 37-42.

[14] Ezenwora, J.A. Development and Performance Evaluation of a Power System Based on the Characterisation and Performance Evaluation of P-V System in Minna, Niger State, Nigeria. A Ph.D Thesis, Department of Physics, Federal University of Technology, Minna, Nigeria; 2016.

\section{Authors' Profiles}

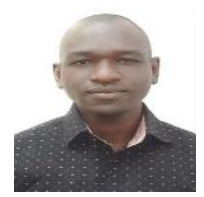

Aku Godwin Ibrahim - Obtained his Ph.D from the Federal University of Technology, Minna, Nigeria in 2015. He received his Masters and Bachelors degree from the University of Agriculture, Makurdi, Nigeria, and University of Jos, Nigeria in 2006 and 2002 respectively. $\mathrm{He}$ is currently a Senior Lecturer at the department on Physics, Federal University of Technology, Minna, Nigeria. His primary research interests are in the area of Physics Electronics and Communication/Atmospheric Physics.

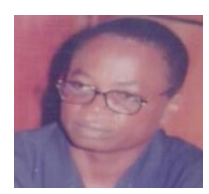

Onyedi David Oyedum - Obtained his Bachelor's Degree in 1977 from The University of Nigeria, Nsuka. His Masters Degree was obtained from The Ahmadu Bello University, Zaria, Nigeria in 1982 and Ph.D from The Federal University of Technology, Minna, Nigeria in 2005. $\mathrm{He}$ is serving as a Professor in the department of Physics, Federal University of Technology, Minna, Nigeria. His research interests are in the area of Communication/Atmospheric Physics and Physics Electronics.

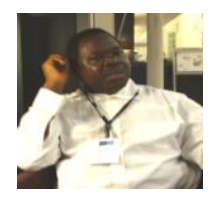

Omotayo Bamidele Awojowogbe - Received his B.Sc degree in Physics and Engineering Physics from the Ondo State University, Ado Ekiti (now University of Ado-Ekiti), Nigeria in 1987, M.Sc in Theoretical Physics, University of Ibadan, Nigeria in 1991 and PhD from Federal University of Technology Minna, Nigeria. In collaboration with the Institute of Biomedical Engineering and Medical informatics, Swiss Federal Institute of Technology (ETH Zurich) and the University of Zurich, in 1997. He won the 2003 Young African Mathematician Medal Award by African Mathematical Union at the International Conference of Mathematical Sciences (AMU-ICMS).

$\mathrm{He}$ is a professor of Physics in the department of Physics, Federal University of Technology, Minna, Nigeria and an assosiate member of the Abdul Salam International Centre for Theoretical Physics (ICTP), Trieste, Italy. His field of research is Theory, Dynamics and Applications of the analytical solutions of the Bloch NMR flow equations.

How to cite this paper: Aku G. Ibrahim, Onyedi D. Oyedum, Omotayo B. Awojowogbe,"Implementation Procedure for a Designed Stand-alone, Auto-Frequency Select Ultrasound Pest Control Device for Field Applications", International Journal of Engineering and Manufacturing(IJEM), Vol.8, No.1, pp.38-52, 2018.DOI: 10.5815/ijem.2018.01.04 